University of Nebraska - Lincoln

DigitalCommons@University of Nebraska - Lincoln

$1-1-2004$

Institutions and Agricultural Productivity in Sub-Saharan Africa

Lilyan E. Fulginiti

University of Nebraska-Lincoln, Ifulginiti1@unl.edu

Richard K. Perrin

University of Nebraska-Lincoln, rperrin@unl.edu

Yu Bingxin

University of Nebraska-Lincoln

Follow this and additional works at: https://digitalcommons.unl.edu/ageconfacpub

Part of the Agricultural and Resource Economics Commons

Fulginiti, Lilyan E.; Perrin, Richard K.; and Bingxin, Yu, "Institutions and Agricultural Productivity in SubSaharan Africa" (2004). Faculty Publications: Agricultural Economics. 10.

https://digitalcommons.unl.edu/ageconfacpub/10

This Article is brought to you for free and open access by the Agricultural Economics Department at DigitalCommons@University of Nebraska - Lincoln. It has been accepted for inclusion in Faculty Publications: Agricultural Economics by an authorized administrator of DigitalCommons@University of Nebraska - Lincoln. 
January 2004

\title{
Institutions and Agricultural Productivity in Sub-Saharan Africa ${ }^{1}$
}

\author{
Lilyan E. Fulginitia, ${ }^{\mathrm{a}}$, Richard K. Perrin ${ }^{\mathrm{a}}$, and Bingxin $\mathrm{Yu}^{\mathrm{a}}$ \\ ${ }^{a}$ Department of Agricultural Economics, University of Nebraska, Lincoln, NE 68583, USA
}

\begin{abstract}
Agricultural productivity in 41 Sub-Saharan Africa (SSA) countries from 1960 to 1999 is examined by estimating a semi-nonparametric Fourier production frontier. Over the four decades the estimated rate of productivity change was $0.83 \%$ per year, although the average rate from $1985-99$ was a strong $1.90 \%$ per year. Former UK colonies exhibited significantly higher productivity gains than others, while Liberia and countries that had been colonies of Portugal or Belgium exhibited net reductions in productivity. We measure a significant reduction in productivity during political conflicts and wars, and a significant increase in productivity among those countries with higher levels of political rights and civil liberties.
\end{abstract}

Key Words: Sub-Saharan Africa, agricultural productivity, institutions, stochastic frontier, Fourier functional form.

\section{Introduction.}

Sub-Saharan Africa is one of the world's poorest regions. Its population and land area are approximately three times that of the USA. The region's economies are heavily dependent on agriculture, which accounts for two-thirds of the labor force, 35\% of GNP and 40\% of foreign exchange earnings. Productivity performance in the agricultural sector is thus critical to

\footnotetext{
${ }^{1}$ A contribution of the University of Nebraska Agricultural Research Division, Lincoln, NE 68583. Journal Series No. 14353. Senior authorship not assigned.

${ }^{2}$ Corresponding author: lfulginti@unl.edu, 307C Filley Hall, Department of Agricultural Economics, University of Nebraska, Lincoln, NE 68510, USA. Tel (402) 472-0651, fax (402) 472-3460.
} 
improvement in overall economic well-being in Sub-Saharan Africa (SSA), and it has therefore been the subject of at least seven multi-country studies (Block (1994), Frisvold and Ingram (1995), Thirtle, et al.(1995), Lusigi and Thirtle (1997), Rao and Coelli (1998), Chan-Kang et al. (1999), Suharyanto, et al.(2000) and FAO (2000).) These studies, though they covered different time periods and different sets of SSA countries, have been reasonably consistent in reporting positive average productivity gains during the 1960's, regression or no gain in productivity during the 1970's, with a recovery to positive gains during the 1980's and early 1990's. The present study aims to provide a more comprehensive understanding of agricultural productivity growth in this region, and the potential role of colonial heritage and other institutional factors that might give additional insights on the differences between countries.

\section{Analytical Approach.}

Productivity is defined as output per unit of input. Productivity growth aims at capturing output growth not accounted for by growth in inputs. We address two questions about agricultural productivity in SSA. First, what have been the rates of productivity growth? Second, what institutional and socio-political factors may have affected agricultural productivity performance in SSA in the last four decades?

Among the many alternatives available to estimate productivity growth, the one we adopt is the production function approach pioneered by Solow and Griliches and used by many others in the multi-country context. Aigner, Lovell and Schmidt and Meeusen and Van den Broeck modified the production function to allow for the presence of technical inefficiencies captured by a one-sided error term. This standard neoclassical production function is re-labeled a stochastic production frontier and following Battese and Coelli (1995) is written: 
(1) $\quad \ln Y_{i t}=f\left(x_{i t}, t ; \beta\right)+v_{i t}-u_{i t} \quad i=1, \ldots, I, \quad t=1, \ldots, T$

where $Y_{i t}$ is output of the $i$-th country in time period $t, x_{i t}$ is an $N x l$ vector of the logarithm of inputs for the $i$-th country in time period $t, \beta$ is a vector of unknown parameters, $v_{i t}$ are random variables which are assumed to be iid $\mathrm{N}\left(0, \sigma_{v}^{2}\right)$ and independent of $u_{i t}$, and $u_{i t}$ is a non-negative random variable distributed iid $N\left(\eta, \sigma_{u}^{2}\right)$ associated with technical inefficiency across production units (or individual production units effects.) In our case, it accounts for heterogeneity across countries that can cause departures from maximum potential output.

We use this production frontier to break down the growth rate of aggregate output into contribution from the growth of inputs versus productivity change:

$$
\dot{Y}_{i t}=\sum_{n} \varepsilon_{i t n} \dot{x}_{i t n}+T \dot{F F} P_{i t}
$$

where a dot over a variable indicates its rate of change, and $\varepsilon_{i t n}$ is the production elasticity of input $n$, for country $i$ in year $t, \varepsilon_{n}=\frac{\partial f(x, t, \beta)}{\partial x_{n}}$. In turn, TFP growth can be decomposed as (dropping the it subscripts for simplicity):

$$
\stackrel{\bullet}{T P P}=T C+E C
$$

where $T C=\frac{\partial f(x, t ; \beta)}{\partial t}$, a shift of the production frontier representing technical change, and technical efficiency change, EC, is the rate at which a country moves toward or away from the production frontier, which itself shifts through time as measured by TC.

The technical efficiency change component requires a little more explanation given that it will also be the basis for information that will lead us to answer the second question, the identification of institutional and political factors that underlie differential productivity growth 
performance across countries in SSA. Technical inefficiency is captured in equation (1) by the non-negative random variable $u$. The ratio of observed output for the $i$-th country relative to its potential output when the individual country effects are zero, is used to define the technical efficiency of the $i$-th country in period $t, T E_{i t}=\frac{Y_{i t}}{\exp \left[f\left(x_{i t} ; \beta\right)+v\right]}=\exp \left(-u_{i t}\right)$. This measure of technical efficiency takes on values of zero to one, with a value of one indicating full technical efficiency. It represents the observed output of the $i$-th country at time $t$ relative to the output produced by a fully efficient country using the same input vector. The change in $T E$ between two periods is $E C$.

Given that the $T E$ term indicates discrepancies in the productivity performance across countries, the frontier methodology lends itself to the inclusion of potential determinants of country heterogeneity which we refer to as 'efficiency changing variables'. We follow Battese and Coelli and specify a frontier model where the technical inefficiency effects are defined to be an explicit function of country-specific institutional and socio-political variables. The technical inefficiency effect $u_{i t}$ for the $i$-th country in the $t$-th period has a truncated iid $N\left(\eta_{i t}, \sigma_{u}{ }^{2}\right)$ distribution, where the mean is

$$
\eta_{i t}=h_{i t} \delta
$$

in which $h_{i t}$ is a (1xp) vector of variables that influence the efficiency of the country, and $\delta$ is a ( $p$ x1) vector of unknown parameters to be estimated.

For implementation, the production function in (1) is approximated with a specific functional form that imposes minimal a priori assumptions, a flexible form. Two algebraic approximations to the production function (1) have been used in the literature, Taylor series and Fourier series, with the first being more common than the last. Gallant $(1981,1982)$ argues convincingly for the superiority of the Fourier approximation in economic applications. This 
approximation of the true function has been shown by El Badawi, Gallant, and Souza (1982) to approximate both the function itself and its derivatives. Following Gallant we use the Fourier flexible form, a semi-nonparametric form that combines a standard translog function with a nonparametric Fourier series. This form has not been used before in primal space to approximate a production function or in the context of a production frontier. Details on the construction of this form, as well as other details not reported here, can be found in Fulginiti, et al.

\section{Data}

Panel data on output and conventional agricultural inputs (land, labor, fertilizer, tractors and animals) for 41 SSA countries for 1961-1999, are available from the FAOSTAT website. These data have been used in nearly every previous study of agricultural productivity in SSA countries. Summary statistics for the data set and other details of the data set may be found at Fulginiti, et al.

Agricultural output is expressed as the quantity of agricultural production in millions of 1989-1991 “international dollars”. We refer to land, labor, livestock, machinery and fertilizer as traditional inputs. Agricultural land is measured as the sum of arable land and permanent crops in thousand hectares. Agricultural labor is measured as the number of persons who are economically actively engaged in agriculture, in thousands. The livestock variable is a weighted average of the number of animals on farms in thousands. The farm machinery variable is the number of agricultural tractors. Fertilizer is quantity of fertilizer plant nutrient consumed (N plus $\mathrm{P}_{2} \mathrm{O}_{5}$ plus $\mathrm{K}_{2} \mathrm{O}$ ), in metric tons.

Two types of efficiency changing variables are considered in this analysis, those that allow for qualitative input differences and those that may capture differences in the institutional 
and socio-political environment across countries. In addition a dummy variable is included for Ethiopia for years after the secession of Eritrea in 1992. As there is no data for Eritrea prior to this date, we merge the data for both countries for the period 1992-1999 and call it Ethiopia.

Data availability restricts us to three input quality measures: (a) Labor quality proxied by adult illiteracy rate taken from the World Development Indicators 2001; (b) land quality proxied by percentage of land irrigated; and (c) a dummy variable for drought equal to one for a year in which a drought was identified in the country either by the Keck and Dinar study or the African Development Indicators, 2002, zero otherwise.

The institutional variables are as follows. (a) Colonial heritage represented by three dummy variables for countries that were colonies of (or within the sphere of influence of) Great Britain, France, and Portugal (versus former Belgian colonies, Liberia and Ethiopia as the reference set), as determined from the Encyclopedia Britannica. (b) Independence, represented by the number of years since independence, as determined from the Central Intelligence Agency World Factbook. (c) Armed conflict, represented by three dummy variables to indicate minor conflict, intermediate conflict and war (contrasted with no conflict), using data from Gleditsch et al. (d) Political rights/civil liberties, represented by two dummy variables categorizing countries as free or partly free (contrasted with not free) from the Freedom House index of political rights and civil liberties. Because the Freedom House variables are available only for the years 19721999, this shorter time series of 1148 observations will be referred to as the "freedom data", as opposed to the 1599 observations "base data" of all other variables that are available for 19611999. 


\section{Estimation}

We estimate the Fourier flexible functional form using both the base data for 41 countries, and the freedom data for the same countries. Denote with $i=1, \ldots, 41$ the countries, and with $j$ and $k=1, \ldots, 5$ the inputs $x_{i j t}$ and $x_{i k t}$ at each time period $t=1, \ldots, 39$. Imposing symmetry, the Fourier production frontier we estimate is:

(6) $\ln Y_{i t}=u_{0}+\sum_{j=1}^{5} b_{j} x_{i j t}+\frac{1}{2} \sum_{j=1}^{5} c_{j j} x_{j j}^{2}+\sum_{j=1}^{5} \sum_{k>j}^{5} c_{j k} x_{i j t} x_{i k t}+b_{t} t+\frac{1}{2} b_{t t} t^{2}+\sum_{j=1}^{5} b_{j t} x_{i j t} t$

$$
\begin{aligned}
& +\left[m_{t} \cos \left(z_{t}\right)+n_{t} \sin \left(z_{t}\right)\right]+\sum_{j=1}^{5} \sum_{k>j}^{5}\left[m_{j k} \cos \left(z_{i j t}-z_{i k t}\right)+n_{j k} \sin \left(z_{i j t}-z_{i k t}\right)\right] \\
& +\sum_{j=1}^{5} \sum_{k>j}^{5}\left[m_{j k 1} \cos \left(z_{i j t}-z_{i k t}-z_{t}\right)+n_{j k 1} \sin \left(z_{i j t}-z_{i k t}-z_{t}\right)\right] \\
& +\sum_{j=1}^{5} \sum_{k>j}^{5}\left[m_{j k 2} \cos \left(z_{i j t}-z_{i k t}+z_{t}\right)+n_{j k 2} \sin \left(z_{i j t}-z_{i k t}+z_{t}\right)\right] \\
& -u_{i t}+v_{i t}
\end{aligned}
$$

where $Y$ is agricultural output; $x$ 's are logarithms of inputs (land, labor, livestock, machinery, and fertilizer); $t$ is time from 1 to 39 (a proxy for technical change); $z$ 's are rescaled $x$ 's and $t ; k$ designates a "multi-index" vector of integers that creates a specific index of the $z_{i}{ }^{\prime} s ; b, c, m, n$ are parameters to be estimated, $u$ is the one-sided technical inefficiency term assumed truncated at zero and distributed iid $N\left(\eta, \sigma_{U}^{2}\right)$ that captures heterogeneity across countries and is the basis for differences in technical efficiency. In order to allow for measurement error and other random factors the Fourier frontier is augmented with a random error $v$, an iid $N\left(0, \sigma_{v}{ }^{2}\right)$ that is independent of $u$. The technical inefficiency term is specified as the following function of efficiency-changing variables, estimated simultaneously with equation (6):

$$
u_{i t}=h_{i t} \delta+\xi_{i t}
$$

with random variable $\xi_{i t}$ sharing the distributional characteristics of random variable $u_{i t}$. 
The simultaneous maximum-likelihood procedure of the FRONTIER 4.1 program

(Coelli, 1996a) was used to estimate the 88 parameters in equation (6), 60 of which are Fourier terms, and the 13 parameters (15 using the freedom data) in equation (7). These estimates are the benchmark used to perform the tests below and are referred to as the "full" model. Details of parameter estimates and test statistics are available in Fulginiti, et al.

Three sets of specification tests were performed. In the first the likelihood ratio tests indicate that technical change was not Hicks-neutral. ${ }^{3}$ In the second the likelihood ratio tests reject elimination of several subsets of efficiency changing variables, indicating that the full frontier model with all the country-specific variables in the efficiency term is appropriate. ${ }^{4}$ In the third set of tests we used likelihood ratios to compare six functional forms nested within the model of equation (6), in accordance with the principle of downward selection. The functional forms, estimated using both data sets, were: a 68 parameter Fourier form with 40 Fourier terms; a 48 parameter Fourier form with 20 Fourier terms; a 30 parameter Fourier form with 2 Fourier terms; a 28 parameter translog form, and a 7 parameter Cobb-Douglas form. ${ }^{5}$ For all these tests,

\footnotetext{
${ }^{3}$ The likelihood-ratio test statistic with both the base and the freedom data for the null hypothesis of no technical change is calculated to be 356.92 and 287.84 respectively, exceeding the $1 \%$ critical value 76.15 with 49 degrees of freedom. The likelihood-ratio test statistic with both the base and the freedom data for the null hypothesis of Hicksneutral technical change is calculated to be 330.2 and 233.68 respectively, exceeding the $1 \%$ critical value with 45 degrees of freedom.

${ }^{4}$ Three tests are performed with both the base and the freedom data. The first one tests the null of no technical inefficiency (or the appropriateness of the one-sided error specification), the second test the null hypothesis of no country specific factors influencing technical inefficiency by setting the parameter $\gamma$ (a ratio of standard errors) and all parameters in equation (7) to zero, the third tests the null that the parameters for subgroups of the efficiency changing variables are zero. Likelihood ratios for the first test are: 441.24 and 303.92 with 15 degrees of freedom for the base and freedom data respectively, rejecting at 99\% significance level. Likelihood ratios for the second test are: 374.32 and 303.92 with 13 degrees of freedom respectively, rejecting at $99 \%$ significance level. Likelihood ratios for the third tests also reject the null for all four subgroups at the $99 \%$ significance level for both models.

5 The Cobb-Douglas model only includes the linear terms in inputs and time. The Translog model adds the second order Taylor approximation terms to the Cobb-Douglas form. The first Fourier model includes the Translog model and the first order Fourier terms of the time trend, $\cos \left(z_{t}\right)$ and $\sin \left(z_{t}\right)$. Ten pairs of first order Fourier terms of input ratios, $\cos \left(z_{i j t}-z_{i k t}\right)$ and $\sin \left(z_{i j t}-z_{i k t}\right)$, are added to obtain the next Fourier flexible form. The next model adds the
} 
equation (7) included all 12 efficiency-changing variables (14 with the freedom data.)

Likelihood ratio tests caused us to reject, in every case, the hypothesis of a lower order form contrasted with the next higher order form. By this criterion, then, the Fourier series terms constitute significant additions to the model. The results imply that the full 68-parameter Fourier model of equations (6) and (7) produces estimates of the production function and its derivatives (therefore of technical change) with the least amount of approximation error.

It is at this point that we introduced the second criterion for model evaluation, consistency of the estimated function with the properties implied by production theory. We calculate production elasticities for each of the models estimated above to evaluate monotonicity. Of all the forms, the Cobb-Douglas was the only one with no violations of monotonicity (positive production elasticities). Expanding the specification from the 7-parameter CobbDouglas to the 28-parameter translog created violations at about 90\% of data points; adding in addition the first two Fourier terms increased this percentage slightly; and adding the higherorder Fourier terms resulted in violations at $99-100 \%$ of the data points (details available at Fulginiti, et al.) A high percentage of such violations has been a common finding among panel studies of this type, as well as Monte Carlo studies (Fleissig, et al.). For SSA agriculture, for example, the studies by Chan-Kang, et al., and by Thirtle, et al., report 100 percent monotonicity violations. Thus as we added trigonometric terms we added instability to the functional form by capturing small fluctuations in the data, even though statisitical tests indicate that the higherorder terms minimize specification bias. This problem of a bias-stability tradeoff in choosing the

Fourier terms of the form $\cos \left(z_{i j t}-z_{i k t}-z_{t}\right)$ and $\sin \left(z_{i j t}-z_{i k t}-z_{t}\right)$, an addition of 10 pairs. The full model of equation (6) adds the Fourier terms of the form $\cos \left(z_{i j t}-z_{i k t}+z_{t}\right)$ and $\sin \left(z_{i j t}-z_{i k t}+z_{t}\right)$, an addition of 10 pairs. 
number of Fourier terms has been previously identified by Gallant (1981, 1982), Chalfant, Mitchell and Onvural, Terrell and Dashti, Fleissig, Kastens and Terrell and others.

We do not know of any formal method of resolving this tradeoff, so we proceed in an adhoc manner and choose the simplest Fourier form considered, which allows us to more flexibly estimate the time path of technical change:

$$
\begin{aligned}
\ln Y_{i t} & =u_{0}+\sum_{j=1}^{5} b_{j} x_{i j t}+\frac{1}{2} \sum_{j=1}^{5} c_{j j} x_{j j}^{2}+\sum_{j=1}^{5} \sum_{k>j}^{5} c_{j k} x_{i j t} x_{i k t}+b_{t} t+\frac{1}{2} b_{t t} t^{2}+\sum_{j=1}^{5} b_{j t} x_{i j t} t \\
+ & {\left[m_{t} \cos \left(z_{t}\right)+n_{t} \sin \left(z_{t}\right)\right]-u_{i t}+v_{i t} }
\end{aligned}
$$

with inefficiency specified as in (7). The first derivative of (8) with respect to $t$ allows us to evaluate the rate of technical change, TC:

$$
\mathrm{TC}_{i t}=b_{t}+b_{t t} t+\sum_{j=1}^{5} b_{j t} x_{i j t} t+\left[m_{t} \cos \left(z_{t}\right)-n_{t} \sin \left(z_{t}\right)\right] \lambda
$$

where $\lambda$ is a common scaling factor (see Fulginiti, et al.)

We simultaneously fit equations (7) and (8) with a total of 28 translog parameters, 2 Fourier terms that approximate technical change, and 13 inefficiency parameters with the base data (15 with the freedom data.) For the base data, twenty-one out of forty-three parameters are significantly different from zero at the 95\% confidence level while twenty-five of forty-five are significant using the freedom data (details available at Fulginiti, et al.) These parameters are used in equation (9) to evaluate technical change at each data point.

It is not very informative to discuss the average rate of technical change for all countries and years, because grand averages "hide" information. We find it more informative to look at the evolution of the annual average TC for the base and freedom models, evaluated using equation (9.) From the evolution of average TC shown in Figure 1 there are two obvious conclusions. First, the Fourier terms have shaped technical change. Second, the rate of technical 
change for the whole region was negative in the 60's and 70's and turned positive during the 80's and 90's.

Another empirical result of interest is the nature of the efficiency change, as reflected in the estimates of $\delta$ from equation (7). We can see in Table 1 that the effect of illiteracy is insignificant, that irrigation decreases inefficiency and drought increases it. While Chan-Kang, et al., found illiteracy significant, Thirtle, et al., found it insignificant. The drought and irrigation results support the findings in the studies by Block, Frisvold and Ingram, Thirtle et al., and Chan-Kang et al. With respect to the institutional variables, accounting for colonial history seems to be important, as well as political rights and civil liberties. The coefficients associated with a higher level of political rights and civil liberties indicate that the more these rights are respected, the more efficient is the country's agriculture, a result consistent with Chan-Kang, et al. The variables indicating years since independence and the presence of conflict are not individually significant, though they are significant as a group. ${ }^{6}$

\section{Agricultural Productivity Performance in SSA}

Our objectives have been to obtain measures of SSA agricultural productivity covering the most complete set of countries and years to date, and to explore the potential role of institutional variables in understanding differences between the performances of individual countries. The pooled frontier production function of the previous section provides the basis for addressing these objectives. We find that the area achieved average annual productivity gains of

\footnotetext{
${ }^{6}$ Likelihood ratio tests of the base and freedom data are 12.2 and 145.8 respectively with 3 degrees of freedom, rejecting the null at the $99 \%$ and $90 \%$ confidence levels respectively
} 
$0.83 \%^{7}$ over the four decades . (All cross-country averages reported here are weighted by current share of SSA agricultural output.) This is consistent with the $0.49 \%$ estimated by FAO for approximately the same period and countries. It is quite different from the $-.086 \%$ estimated by Suhariyanto, et al., although the decade-by-decade time path found in that study is nonetheless quite similar to ours.

Average gains were positive for each decade except the 1970's, when average productivity declined at the rate of $0.3 \%$ per year (Figure 2, Table 2). We find no readily evident causes for the failure during the 1970 's. Drought was not unusually prevalent during that decade (drought was very widespread during 1982-84, but does not appear to reduce productivity during those years.) Wars and civil disturbances do not appear to be more severe during those years, either. Since 1985, average productivity gains for SSA agriculture have been quite strong, averaging $1.90 \%$ per year, a level comparable to those in industrialized countries. The "recovery" first noted by Block for the years 1983-88 seems to have persisted, despite his pessimism about that possibility.

\section{Colonial heritage}

In Table 3 we report the four-decade productivity growth rates for the individual countries. We have grouped the countries according to their colonial heritage, and it is evident that there are very substantial differences between these groups. The four former Portuguese colonies had the poorest performance, averaging $-0.26 \%$ per year, with Liberia (former U.S. protectorate) about the same at $-0.25 \%$, the three former Belgian colonies next poorest with $-0.17 \%$ per year. The14 former French colonies came next with a positive average productivity

\footnotetext{
${ }^{7}$ When Nigeria and South Africa, representing 17 percent and 13 percent respectively of production and having a 1.6 percent TFP growth are purged from the set, weighted average TFP for the rest of the countries is 0.43 percent.
} 
gain of $0.52 \%$, Ethiopia with an average productivity gain of $0.76 \%$, while the 18 former British colonies performed the best with an average $1.08 \%$ productivity gain per year.

Figure 3 charts these differences by colonial heritage groupings. It shows that trends, as well as levels, differ among the groups. The three Belgian colonies have done badly during the 90 's because of armed conflicts, resulting in a marked downward trend in the rate of productivity change over the four decades. The UK group showed not only the highest average level of productivity gains, but one of the highest growth rates in TFP gains, as well. The four exPortuguese colonies have had the strongest upward trend since the disastrous 1970's, achieving gains approximately equal to the ex-French colonies during the 1990's.

We note that within the British group, Nigeria and South Africa not only posted the highest productivity gains, $1.64 \%$ per year for each, but they are also the largest countries, constituting an average of $17 \%$ and $13 \%$ of SSA agricultural output over this period, respectively. Thus they are significant contributors to the relatively high productivity rates for the UK group. But the remaining 16 British countries nonetheless averaged a positive $0.32 \%$ productivity gain per year, with only six ${ }^{8}$ experiencing overall deterioration in productivity.

\section{Years since independence}

One issue related to the time of independence is the path of productivity growth after independence. The regression results in Table 1 indicated a slightly positive (but statistically insignificant) trend in technical efficiency after independence. To picture the path of productivity after independence, we plot in Figure 4 the average rate of productivity growth experienced by all countries in a given year since independence (average is in this case a simple

\footnotetext{
${ }^{8}$ These are Botswana, Gambia, Lesotho, Malawi, Somalia, and Uganda.
} 
average across countries.) The path is quite erratic, though inspection and the quadratic trend line offer some evidence that productivity tends to be stagnant or decreasing during the first 12 years of independence, tending to increase thereafter.

\section{Political Rights and Civil Liberties}

As previously mentioned, we have acquired two indexes of political freedom that Freedom House has published for these and other countries, but they became available only beginning in 1972. Each year Freedom House has rated each country as "not free", "partly free", or "free", based on a series of checklists relating to political rights and civil liberties. To obtain an econometric estimate of the effect of political freedom, we re-estimated the Fourier form with data for the 1973-1999 period, including one dummy variable for "partly free" and another for "free." The results of this regression were in all respects very similar to those obtained with the base data for 1962-1999. The correlation between country average TFP measures predicted by the two models was 0.77 , and that between aggregated annual average TFP measures was 0.98 .

The coefficient of the "Partly Free" dummy was -0.26, and that of the "Free" dummy variable was -0.39 , both highly significant. The interpretation is straightforward - in a year in which a country was rated "Partly free", the country is predicted to be $26 \%$ more technically efficient than when not free. In a year in which it was rated "Free", it is predicted to be $39 \%$ more efficient. From these results and average levels of the variables by country, it is reasonable to infer that average differences in political freedom between former Portuguese and former UK colonies, for example, explain a difference in technical efficiency of about $10 \%$, and a difference in productivity level of the same amount. As discussed in the previous section, however, it is change in freedom that would impact productivity gains or losses, so it appears that there is 
ample opportunity for all of these countries to improve their agricultural efficiency and productivity by increasing political rights and civil liberties.

Our results indicating the effect of colonial heritage on agricultural productivity growth corroborate previous findings by Bertocchi and Canova (2002), Grier (1999), Landes (1998) and North, et al., (1998), all of which found former British colonies to achieve higher per capita GDP growth rates than former French or Portuguese colonies. The explanations they advance for these differences are that institutions such as property rights, political freedom, free markets, etc., do matter in determining the vigor of economic growth. In our study, it is clear that respect for political and civil rights and absence of conflict are two of the institutional characteristics that contribute to the differences between the colonial groups with regard to agricultural productivity performance.

\section{Conclusions}

In this study of agricultural productivity in 41 Sub-Saharan Africa countries, we have found that the region made some progress in the 1960's, suffered a regression in productivity during the 1970 's, but after the mid-1980's recovered to achieve a reasonably robust rate of productivity improvement through the end of the century. The over-all average rate of productivity growth for the four decades was estimated at $0.8 \%$ per year. The general nature of these results is consistent with several other studies of agricultural productivity in parts of SSA published since 1995, which should not be too surprising since the basic data sources are virtually the same. However, our analytical approach was quite different from any other study, with a broader geographical scope, and this provides some confidence in the robustness of the 
estimates. Robustness is particularly useful in the case of SSA agriculture because of the limitations in the quantity and quality of data needed for the purpose.

We estimated TFP gain or loss for each country in each year as the sum of predicted change in the production frontier in that vicinity plus predicted change in technical efficiency for that country and year. We used the Battese-Coelli approach to estimate the efficiency effects of institutional and other efficiency-changing variables, with the production frontier specified as Gallant's Fourier flexible form. We found, as have others, that the use of a fully-parameterized Fourier flexible form (60 Fourier parameters in our case) could be justified by goodness-of-fit criteria, but created violations of the required monotonicity property. Balancing these two criteria subjectively, we chose a very abbreviated Fourier form with only sine and cosine Fourier expansions of the time trend, which allowed us to retain flexibility in estimating the time path of technical change over the four-decade period.

A primary objective of the study was to examine the relationship between growth in productivity and institutional factors, following a number of recent studies showing that GDP growth rates are strongly affected by those factors. We found that 19 ex-British colonies experienced the highest TFP growth rates of colonial groupings, with three ex-Belgian colonies and Liberia the worst performers (their TFP diminished over the period), and 14 ex-French and four ex-Portuguese colonies having intermediate performance levels. These differences were determined in significant measure by the estimated effects of wars and civil conflicts and differences in political and civil liberties as measured by Freedom House indexes. These results indicate that institutional factors are important determinants of agricultural productivity growth, as well as per capita GDP growth as established in other recent studies. 


\section{References.}

Aigner, D. J., C. A. K. Lovell and P. Schimdt. "Formulation and Estimation of Stochastic frontier Production Function Models.” J. Econometrics 6 (1977): 21-37.

Battese, G. E. and T. J. Coelli. "A Model for Technical Inefficiency effects in a Stochastic Frontier Production Function for Panel Data.” Empirical Economics 20 (1995): 325-32.

Bertocchi, G. and F. Canova. "Did Colonization Matter for Growth? An Empirical Exploration into the Historical Causes of Africa's Underdevelopment." European Economic Review 46(2002): 1851-1871.

Block, J. R. “A New View of Agricultural Productivity in sub-Saharan Africa.” Amer. J. Agr. Econ. 76 (November 1994): 619-24.

Chalfant, J. A. "Comparison of Alternative Functional Forms with Application to Agricultural Input Data.” Amer. J. Agr. Econ. 66 ( 2), 1984: 216-220.

Chan-Kang, P. Chan-Kang, S. Wood, J. Roseboom, and M. Cremers. "Reassesing Productivity Growth in African Agriculture.” Paper presented at the AAEA meetings, Nashville, August 1999.

CIA World Factbook. http://www.cia.gov/cia/publications/factbook/ibndex.html

Coelli, T. J. “A Guide to FRONTIER Version 4.1: A Computer Program for Stochastic Frontier Production and Cost Function Estimation.” working paper, Centre for Efficiency and Productivity Analysis (CEPA), Department of Econometrics, University of New England, Armidale, Australia, No. 7/96, 1996 .

Encyclopedia Britannica, http://www.unl.edu:2020/journals/iris/brit.html.

Fleissig, A. R., T. Kastens and D. Terrell. "Evaluating the Semi nonparametric Fourier, AIM and Neutral Networks Cost Function.” Econ. Letters 68 (2000): 235-244.

Food and Agricultural Organization of the United Nations. The State of Food and Agriculture: Lessons from the past 50 years, Rome, Italy, 2000.

Food and Agricultural Organization of the United Nations. FAOSTAT, http://apps.fao.org/page/collections?subset=agriculture.

Freedom House. "Freedom in the World Country Ratings: 1972-72 to 2000-2001.” http://www.freedomhouse.org/ratings/index.htm.

Frisvold, G. and K. Ingram. "Sources of Agricultural Productivity Growth and Stagnation in Sub-Saharan Africa.” Agricultural Economics 13 (1995): 51-61. 
Fulginiti, L., R. Perrin and B. Yu. "Institutions and Agricultural Productivity in Sub-Sahara Africa." Presented at the IAAE meetings, Durban, August 2003. http://agecon.unl.edu/fulginiti/

Gallant, A. R. "On the Bias in Flexible Functional Forms and an Essentially Unbiased Form: The Fourier Flexible Form.” J. Econometrics 15 (1981): 211-45.

Gallant, A. R. "Unbiased Determination of Production Technologies.” J. Econometrics 20 (1982): 285-323.

Gleditsch, N.P., Wallensteen P., Eriksson M., Sollenberg M., Strand H. “Armed Conflict 19462001: A New Dataset.” J. of Peace Research 39(5): 615-637.

Grier, R. M. “Colonial Legacies and Economic Growth." Public Choice 98 (1999): 317-335.

Keck and Dinar. "Water's Sector Management Strategy for SSA," background paper, World Bank.

Landes, D. S. The Wealth and Poverty of Nations: Why some are so rich and some so poor. New York:W.W. Norton \&Co., 1998.

Lusigi, A., and C. Thirtle. "Total Factor Productivity and the Effects of R\&D in African Agriculture”, J. Intl. Development 9 (1997): 529-38.

Meeusen, W. and J. van den Broeck. "Efficiency Estimation from Cobb-Douglas Production Functions with Composed Error.” Intl. Econ. Rev. 18 (1977): 435-444.

Mitchell, K. and N. M. Onvural. "Economies of Scale and Scope at Large Commercial Banks: Evidence from the Fourier Flexible Functional Form.” J. Money, Credit and Banking 28 (2), May 1996: 178-99.

North, D., W. Summerhill, and B. Wengast. Order, Disorder, and Economic Change: Latin America versus North America. New Haven and London: Yale University Press, 2000.

Rao, D. S. P. and T. J. Coelli. "Catch-up and Convergence in Global Agricultural Productivity 1980-1995.” working paper, Center for Efficiency and Productivity Analysis (CEPA), Department of Econometrics, University of New England, Armidale, Australia, No. /98, 1998.

Suhariyanto, K., A. Lusigi and C. Thirtle. "Productivity Growth and Convergence in Asian and African Agriculture.” Africa and Asia in Comparative Economic Persepective, Lawrence, P. and C. Thirtle, Palgrave, New York, 2001.

Terrell, D. and I. Dashti. "Incorporating Monotonicity and Concavity Restrictions into Stochastic Cost Frontiers." Working paper, Department of Economics, Louisiana State University, Baton Rouge, LA, 1997. 
Thirtle, C., D. Hadley and R. Townsend. "Policy-induced Innovation in sub-SaharanAfrican Agriculture: A Multilateral Malmquist Productivity Index Approach.”Development Policy Rev. 13 (1995): 323-48.

World Bank. World Development Indicators 2000, CD-ROM, April 2000.

World Bank. African Development Indicators 2000, CD-ROM, April 2000. 
Figure 1. Technical change in SSA during 1961-1999.

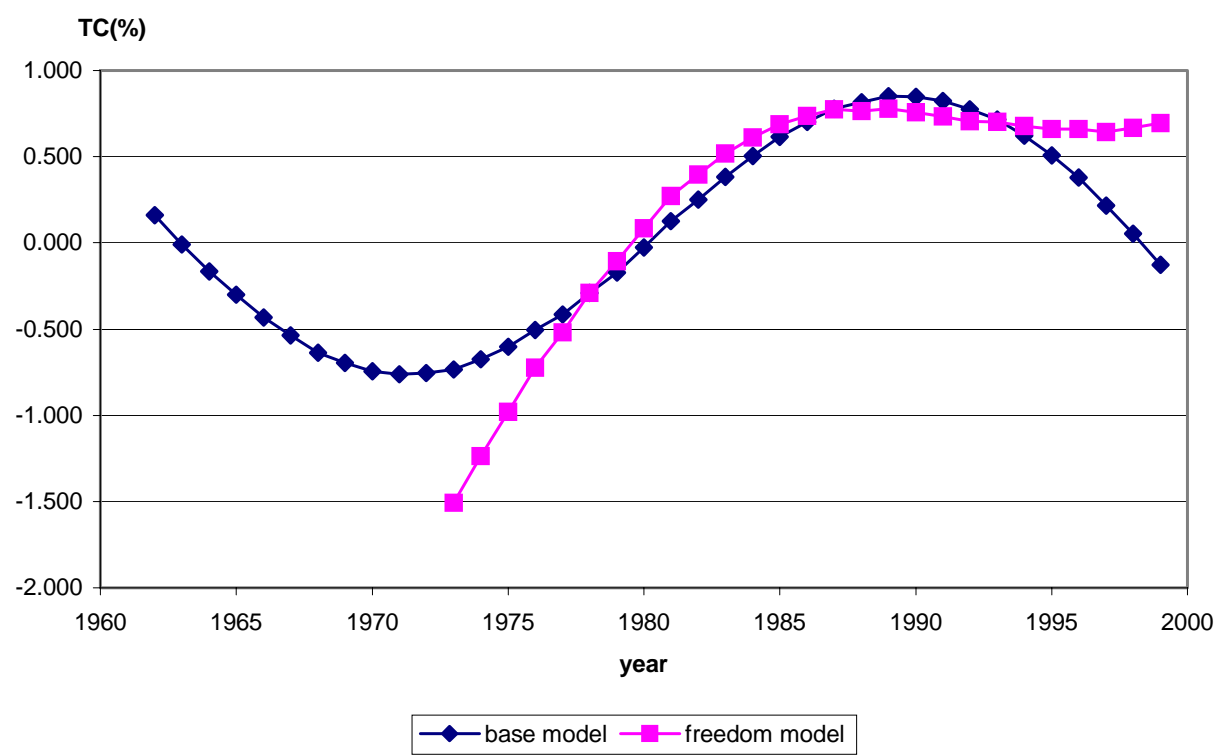

Figure 2. Annual average TFP change in 41 SSA countries.

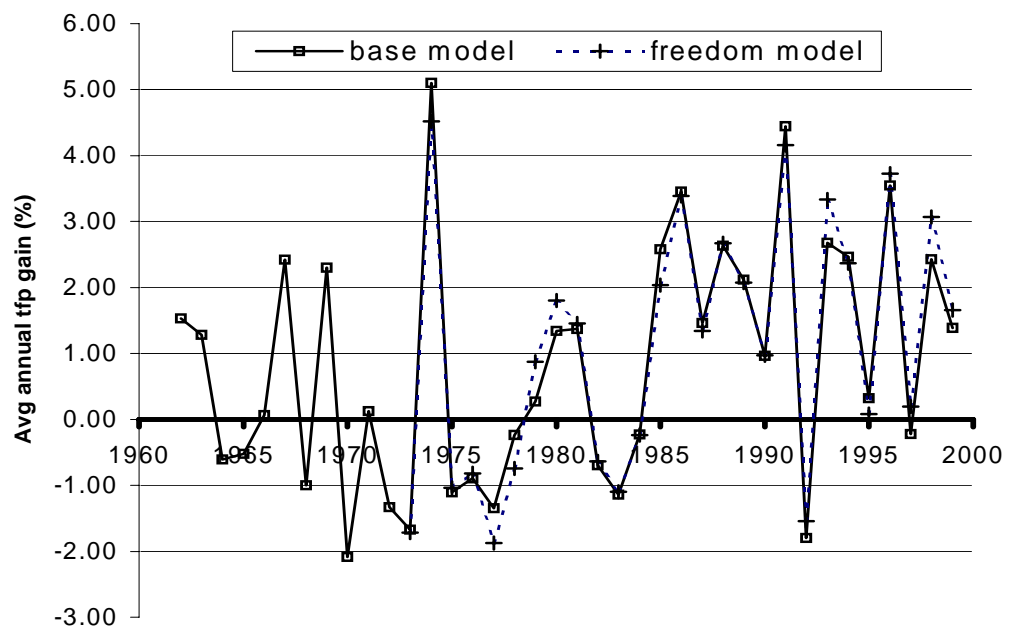


Figure 3. Decade Average TFP by Colonial Heritage Groups

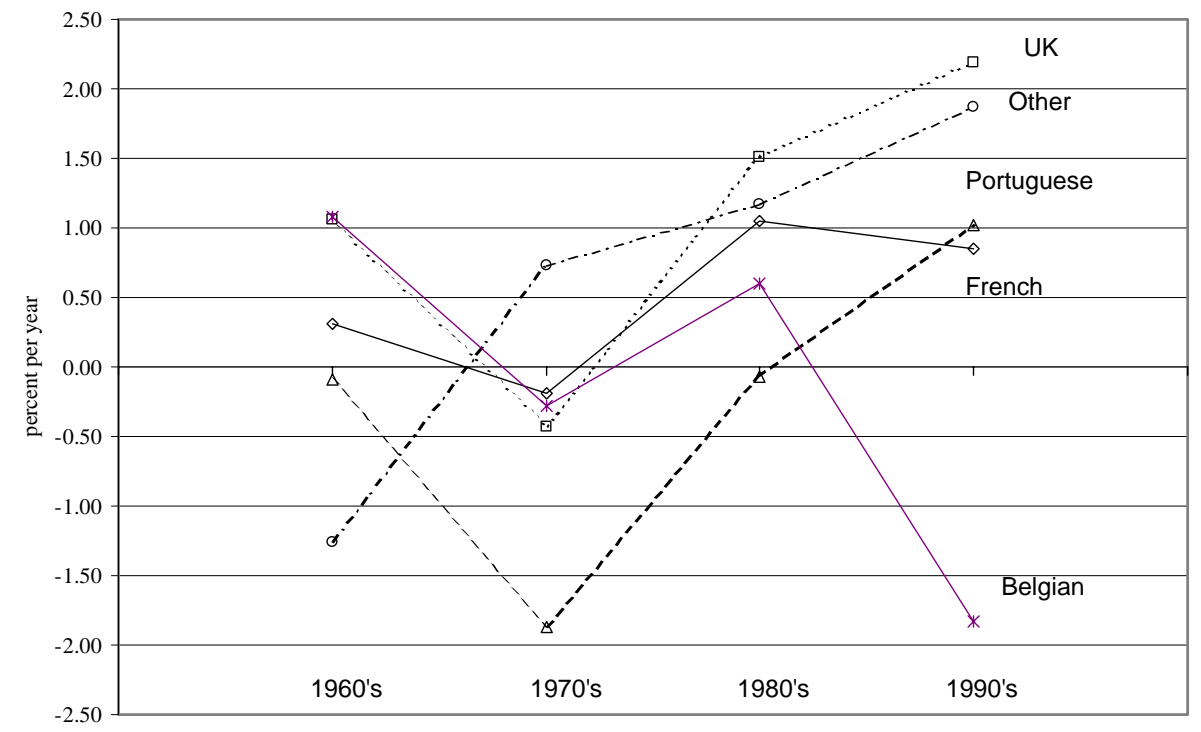

Figure 4. Average annual TFP increase by Years Since Independence

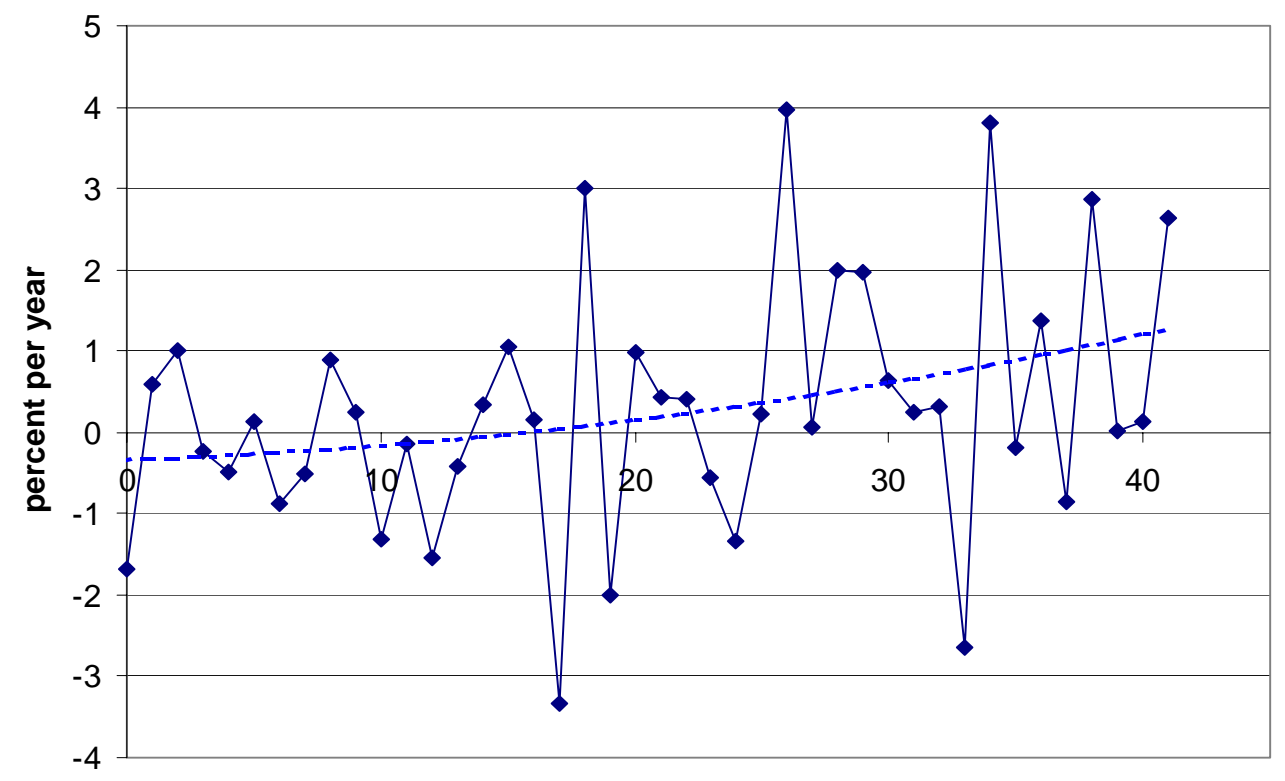


Table 1. Parameter estimates for efficiency changing variables, equation (7).

\begin{tabular}{lllll} 
Variables & estimates (base data) & t-ratio & estimates (freedom data) & t-ratio \\
\hline Efficiency intercept & 0.27 & 1.84 & -0.28 & -0.85 \\
Input quality & & & & -20.61 \\
Irrigation & -0.22 & -24.48 & -0.23 & 2.43 \\
Drought & 0.15 & 3.26 & 0.12 & -0.42 \\
Illiteracy & 0.0005 & 0.63 & -0.0005 & -0.86 \\
Institutional environment & & & & 2.64 \\
Independence & -0.002 & & -0.001 & 0.62 \\
UK & 0.23 & -1.39 & 0.73 & 4.78 \\
France & -0.22 & 2.19 & 0.17 & 0.39 \\
Portugal & 0.75 & -2.13 & 1.25 & -0.34 \\
& & 6.29 & & 1.49 \\
Minor conflicts & -0.11 & & 0.04 & -4.66 \\
Intermediate conflicts & -0.19 & -1.3 & -0.04 & -4.14 \\
War & -0.05 & -1.96 & 0.13 & -1.92 \\
Free & - & -0.73 & -0.39 & -0.26 \\
Partly free & - & - & &
\end{tabular}

Table 2 Average annual TFP change in SSA agriculture, by decade

\begin{tabular}{|ll} 
Decade & $\begin{array}{l}\text { Average TFP change } \\
\text {-----\% per year---- }\end{array}$ \\
1960 's & 0.68 \\
$1970 ' s$ & -0.32 \\
$1980 ' s$ & 1.29 \\
$1990 ' s$ & 1.62 \\
$1961-1999$ & 0.83 \\
\hline
\end{tabular}


Table 3. Average 1962-99 TFP gains by country

\begin{tabular}{|l|l||l|l||}
\hline \multicolumn{2}{|l|}{ Former Belgian colonies: } & \multicolumn{2}{l}{ Former British colonies: } \\
\hline Burundi & -0.99 & Botswana & -0.06 \\
\hline Dem Rep of Congo (Zaire) & -0.12 & Gambia & -1.56 \\
\hline Rwanda & -0.01 & Ghana & 0.34 \\
\hline \multicolumn{1}{|l|}{ average } & $-\mathbf{0 . 1 7}$ & Kenya & 0.68 \\
\hline Former French colonies & & Lesotho & -0.75 \\
\hline Benin & 0.78 & Malawi & -0.06 \\
\hline Burkina Faso & 0.58 & Mauritius & 0.27 \\
\hline Cameroon & 0.87 & Namibia & 0.48 \\
\hline Central African & 0.95 & Nigeria & 1.59 \\
\hline Chad & 0.34 & Sierra Leone & 0.11 \\
\hline Congo & -0.76 & Somalia & -0.64 \\
\hline Côte d'Ivoire & 0.57 & South Africa & 1.64 \\
\hline Gabon & 0.13 & Sudan & 0.66 \\
\hline Guinea & -0.41 & Swaziland & 1.11 \\
\hline Madagascar & 0.04 & Tanzania & 0.75 \\
\hline Mali & 0.51 & Uganda & -0.36 \\
\hline Niger & -0.43 & Zambia & 0.82 \\
\hline Senegal & -0.11 & Zimbabwe & 0.35 \\
\hline Togo & -0.08 & average & $\mathbf{1 . 0 8}$ \\
\hline average & $\mathbf{0 . 5 2}$ & & \\
\hline Former Portuguese colonies: & & Former U.S. colony: \\
\hline Angola & & Liberia & -0.25 \\
\hline Cape Verde & 0.60 & Independent: & \\
\hline Guinea-Bissau & -0.26 & Ethiopia & 0.76 \\
\hline Mozambique & -0.36 & & \\
\hline average & $-\mathbf{0 . 2 6}$ & Ave., all countries & $\mathbf{0 . 8 3}$ \\
\hline
\end{tabular}

